\title{
The Role of Theory in Empirical Second Language Acquisition Research: An Introduction
}

\author{
Ashley Beccia and Paige Yi \\ Teachers College, Columbia University
}

Theory plays a central role in the development of human knowledge. In essence, theory solves puzzles, or questions about observable phenomena that need to be answered, (Kuhn, 1996). Theorizing about solutions to these puzzles requires working at the edge of uncertainty, making bold postulations, and engaging in what renowned philosopher of science Karl Popper terms critical rationalism; it is through the development of theories that are falsifiable and the subsequent empirical testing of those theories that our knowledge about the world (i.e., of natural phenomena) will progress (Popper, 1968).

Despite its omnipresence in papers and journal articles, it is unclear what theory actually denotes and the role that theory plays in the rich vein of scholarship devoted to SLA studies. It seems problematic that a key construct as such for the advancement of research in any scientific field of inquiry is ill-defined and elusive in its status and function. In this light, this forum is an attempt to help put these issues on the agenda of articulate and deliberate discussions within our field of expertise. The contributions in this forum reflect different voices and outlooks gleaned from five graduate students of Teachers College, Columbia University who attended Professor ZhaoHong Han's Advanced SLA course in Fall 2020 devoted to the role of theory in current SLA research enterprise. In particular, Ashley Beccia explores the role theory plays in research on Task-Based Language Teaching (TBLT) for young L2 learners, whilst Paige Yi examines its putative role in empirical studies on the Critical Period Hypothesis ( $\mathrm{CPH})$. Sean Hughes, on the other hand, investigates the role that Sociocultural Theory plays in SLA research. Last but not least, Yanina Tsupa centers on the role played by theory in SLA research on language complexity, accuracy and fluency. Nevertheless, by no means is this forum an exhaustive survey or review of specific theories put to use in the field of SLA. Rather, it is intended to offer some general considerations or even challenges of a leitmotif regarding the status as well as functions of theory within this line of empirical SLA research.

Together, these four papers demonstrate that theory is not a monolith, particularly in the context of SLA. Instead, theory can fulfill different roles and has in fact done so to varying extents across domains of SLA research. In some empirical studies, theory plays a crucial role, serving as the guiding framework or means for making sense of data, whereas in others, theory plays little to no evident role, resulting in studies that are mostly descriptive in nature. The mixture of descriptive studies and those underpinned by theory reflect the advancement of SLA as a scientific discipline (Gass, 2009). As the field matures, more theoretical entities are bound to enter the research picture, with more work yet to be done. In the future, more theory-driven research is seminal to furthering our understanding of L2 acquisition in a principled, coherent and scientifically-grounded way. By making bold conjectures about natural observed phenomena and subjecting these tentative theories to empirical testing, SLA researchers can gain a more

(C) 2021 Beccia \& Yi. This is an open access article distributed under the terms of the Creative Commons Attribution License, which permits the user to copy, distribute, and transmit the work provided that the original authors and source are credited. 
comprehensive understanding of the complex, multi-process phenomena that we call L2 acquisition.

\section{ACKNOWLEDGEMENTS}

We wish to express our gratitude to Professor ZhaoHong Han who provided guidance and feedback in the early stages of formulating ideas for the current forum. We are grateful as well to Peter Kim who provided feedback and support. Our thanks also go to the forum contributors for their insightful commentaries.

\section{REFERENCES}

Gass, S. (2009). A historical survey of SLA research. In W. C. Ritchie \& T. K. Bhatia (Eds.), The New Handbook of Second Language Acquisition (2nd ed., pp. 3-28). Emerald Group Publishing Limited.

Kuhn, T. S. (1996). The structure of scientific revolutions (3rd ed.). Chicago, IL: University of Chicago Press.

Popper, K. R. (1968). Conjectures and refutations: The growth of scientific knowledge. United Kingdom: Harper \& Row.

Ashley Beccia is a doctoral student in Applied Linguistics at Teachers College, Columbia University. Specializing in Second Language Acquisition (SLA), her research interests include Task-Based Language Teaching, child SLA, and language play. Correspondence should be sent to E-mail: ajb2301@tc.columbia.edu

Paige $\mathrm{Yi}$ is a doctoral student in the Applied Linguistics program at Teachers College, Columbia University. Her research interests primarily lie in cross-linguistic phonetics, language policy, as well as socially applied aspects of SLA and multilingualism. Correspondence should be sent to E-mail: pjy2107@tc.columbia.edu 